\title{
Design Of Enhanced Bandwidth Of Dual Element MIMO Antenna For Wireless Applications
}

\author{
${ }^{1}$ B Shruthi, ${ }^{2}$ Dr K Kumar Naik \\ Department of ECE, KLEF, Vaddeswaram, Guntur, India \\ Department of ECE, KLEF, Vaddeswaram, Guntur, India
}

Article History: Received: 11 January 2021; Accepted: 27 February 2021; Published online: 5 April 2021

\begin{abstract}
A multiple-input-multiple-output lightweight printed ultrawideband antenna among a dimension about $40 \times 50 \mathrm{~mm}^{2}$ to minimise the coupling between these two antennas, the proposed antenna with a quarter circular radiating patch, with defected ground structure is designed. The antenna developed by MIMO is highly isolated, stronger than $-15 \mathrm{~dB}$. In the working band, from $2.67 \mathrm{GHz}$ to $14 \mathrm{GHz}$. The simulation indicates that the proposed MIMO antenna will balance the complete enhanced band with a broad bandwidth by making use of CST. It operates at $5.83 \mathrm{GHz}, 8.07 \mathrm{GHz}, 12.28 \mathrm{GHz}$ and bandwidth tends to cover the ultrawideband range. UWB band and high isolation, that assemblesit perfect for any application of wireless modules in the UWB range, in order to minimise coupling. For indoor applications and wireless applications these frequency range is used.
\end{abstract}

Keywords- MIMO antenna; Ultra - wide band applications; High isolation; Defected ground structure;

\section{Introduction}

As of late there has been a lot of attentiveness in creating high information rate frameworks known as ultrawideband (UWB) correspondence frameworks due to the persistently growing scope of remote telecom administrations and allied applications for emulate and information transference. The repetition span of UWB applications confirmed by the Federal Communications Commission (FCC) is somewhere in the $3.1 \mathrm{GHz}-10.6$ $\mathrm{GHz}$ range. In applications where volume, mass, expense, execution, shape compels, low-profile antenna such as miniature equipment is also needed, printed space reception equipment[1].

MIMO antennas is under research as it is having properties like large channel capacity due to multi-antennas, there are many architectures regarding MIMO which can be used to get higher data rates. There are huge number of designs for making a MIMO antenna, some MIMO antennas work not only in high frequency but also in smaller frequencies. Bandwidth is the main reason why we choose MIMO antenna so with respect to atmosphere there is a rise of attenuations and absorptions of the millimetric wave. Closely spaced microstrip MIMO antenna have mutual coupling problem so as per the requirement we need low mutual coupling between antennas in MIMO structure.

The field of communication in [2] is introduced to a new type of antennas called microstrips, which have some distinct advantages compared to the geometry of the antenna. Better performance is one the benefits. Efficiency, low cost, ease of installation and most importantly, low visibility with a confirmed identity. MIMO is a radio communication technology which is being used in many new technologies. Many radio and wireless RF technologies such as Wi-Fi, LTE are using MIMO technology to increase link capacity and spectral efficiency. These MIMO wireless routers are being mostly used.

High speed data rates in a short space of time, wide bandwidth, low power consumption are some panoramas of the Ultra-wide band(UWB) technology that favoured advancements in wireless communication[3]Be that as it may, miniature strip receiving wires naturally having thin data transfer capacities.Consequently, accomplishing wideband in miniature strip receiving wires is unavoidable. In such applications, UWB radio wires are perhaps the most ideal receiving wires to fulfilthe data transfer capacity necessities as they have wideband attributes with minimization[4].Unique receiving wires have been pulling in extraordinary consideration for years and years because of their focal points, for example, basic plan, planar construction, also, expansive transmission capacity. Different arrangements of wideband receiving wires with smaller calculation have been created [4].

Very little appreciation is given to the innovative in antenna engineering when ass compared to the related electronics amplifier advancements, UWB mixers and front-end circuitry have been extensively investigated. Showing the lack of UWB radiating systems research. The academic and industrial societies have realised this. Instruction of sophisticated methods for sustainable and effective digital contact several types of challenges have been presented by various channel features engineers with antennas. The design of an antenna as an antenna has a problem. Instead of differential component of an integral part of electronic systems.

Low coupling execution among the multi-reception apparatus components decides the presentation of multireception apparatus frameworks. Along these lines, MIMO receiving wire decoupling innovation is a hotly debated issue in late investigates. In solitary radio wire decoupling, multi-band receiving wire decoupling, there are various inquiries[5] and dissociate of the UWB antenna[5][6]. Notwithstanding, MIMO-UWB receiving wiredissociate is troublesome in light of the fact that it covers an enormous recurrence band.J.Ren has 
announced a MIMO antenna by putting the receiving wire components in equal and append a limited space uniting it to get excessive disengagement. Thus, the radio wire accomplishes a huge impedance data transmission which balance the whole UWB band in addition to moderate common integratebelow $-15 \mathrm{~dB}$ [5]. To upgrade the presentation about separation, MIMO antenna is introduced by defected ground structure. A high separation had gotten. Nonetheless, construction is composite and that is hard to adapt to down to ground applications[6].After two or three MIMO-UWB gathering gadgets are proposed by utilizing CPW-dealt with procedures and fundamental tuneable fragments to enhance the presentation of MIMO-UWB gathering contraptions in turn to streamline the plan of the antennaformations[7]. Herein, a MIMOantenna is put forward by arranging opening stub among its shared view plane. Antenna is insignificant in size, around UWB band, low coupling arise is secured. The proposed antenna is simulated and designed by using CST in the Time domain for wide band antennas, The time domain of CST better than HFSS. HFSS cannot do simple circuitry co-simulation and new signal type feeding but all of these techniques will perform in CST. In this defected ground structure is used to enhance the antenna bandwidth.

\section{Design Methodology}

Design of proposed antenna has a measurement of $40 \times 50 \mathrm{~mm}^{2}$. The square substrate with relative permittivity of $\square r=2.6$, height of $1.6 \mathrm{~mm}$, and loss tangent of $\tan \delta=0.001$. Two indistinguishable monopole antennas taking care of by microstrip, which is in light of the model in [8], are set one next to the other.Above top layer of PCB, the patch is related among feed line and engraved. With a gap of $8 \mathrm{~mm}$, the two patches are set next to other.By taking cylinder, the patch 1 and patch 2 are attained. A defected ground structure with square shape is used to increase the antenna bandwidth to work in ultrawideband applications. A unique UWB antenna[8] chosen as an essential radio wire element. By using defected ground structure is easier and also increase in bandwidth, and the dimensions of the material are considered as $\mathrm{L} \times \mathrm{W} \times \mathrm{h}$. Copper is the material used by radiative element and the ground plane.Two radio wire components with no decoupling structure between them are put next to each other to shape MIMO antenna 1(patch 1). At that point, an opening is scratched on the shared opinion axis to fabricate the MIMO antenna 2(patch 2).
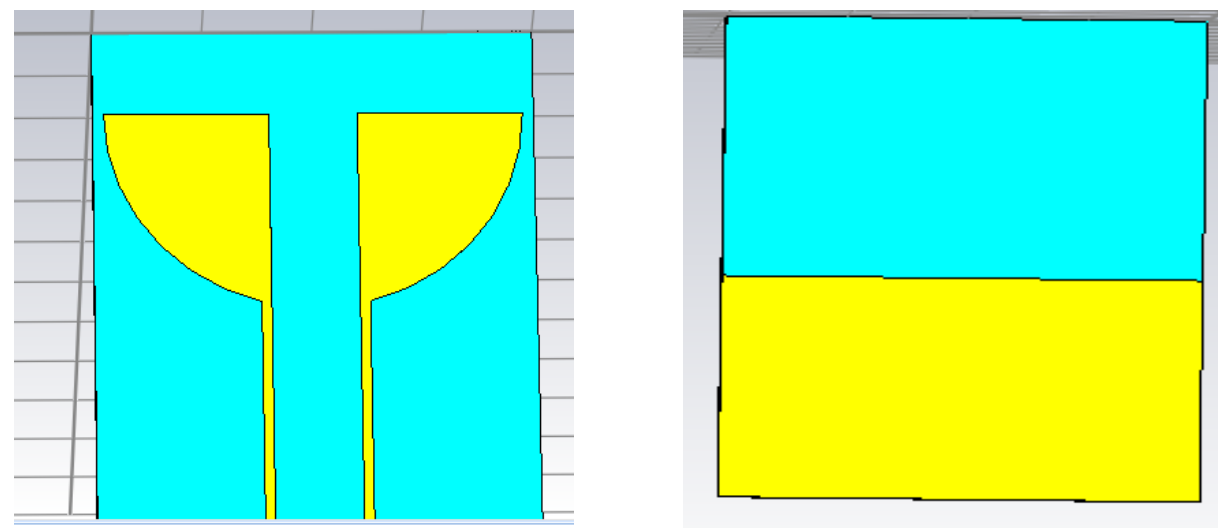

Figure.1 (a) top layer (b) bottom layer

Generate ground with $\mathrm{L} \times \mathrm{W}$ and draw the substrate with height $\mathrm{h}=1.6 \mathrm{~mm}$. By the use of CST software choose a brickfrom the main menu and assign the values width $40 \mathrm{~mm}$ and length $50 \mathrm{~mm}$. Using cylinder make a curve to the patch.

\section{Performance Analysis}

By use of CST software, the results obtained for the antenna are appeared below figure-2(a), 2(b), 2(c), 2(d). Sparameters describe the input-output relationship between ports in an electrical system. S-parameters are the parameters that supports both information and has many advantages for high frequencies. S-parameters $\mathrm{S} 11, \mathrm{~S} 12, \mathrm{~S} 21$ and S22 below -10dB is appeared. Antenna return loss is obtained by the S parameter. In wireless applications a value below $-10 \mathrm{~dB}$ is taken. The proposed antenna design resonates at $2.84 \mathrm{GHz}, 5.2 \mathrm{GHz}$, $8.07 \mathrm{GHz}, 9.48 \mathrm{GHz}, 12.29 \mathrm{GHz}$ and resonates at $-17.14 \mathrm{~dB},-20.69 \mathrm{~dB},-27.94 \mathrm{~dB},-31.27 \mathrm{~dB},-42.46 \mathrm{~dB}$, and covering band from $2.42 \mathrm{GHz}$ to $14.7 \mathrm{GHz}$. 


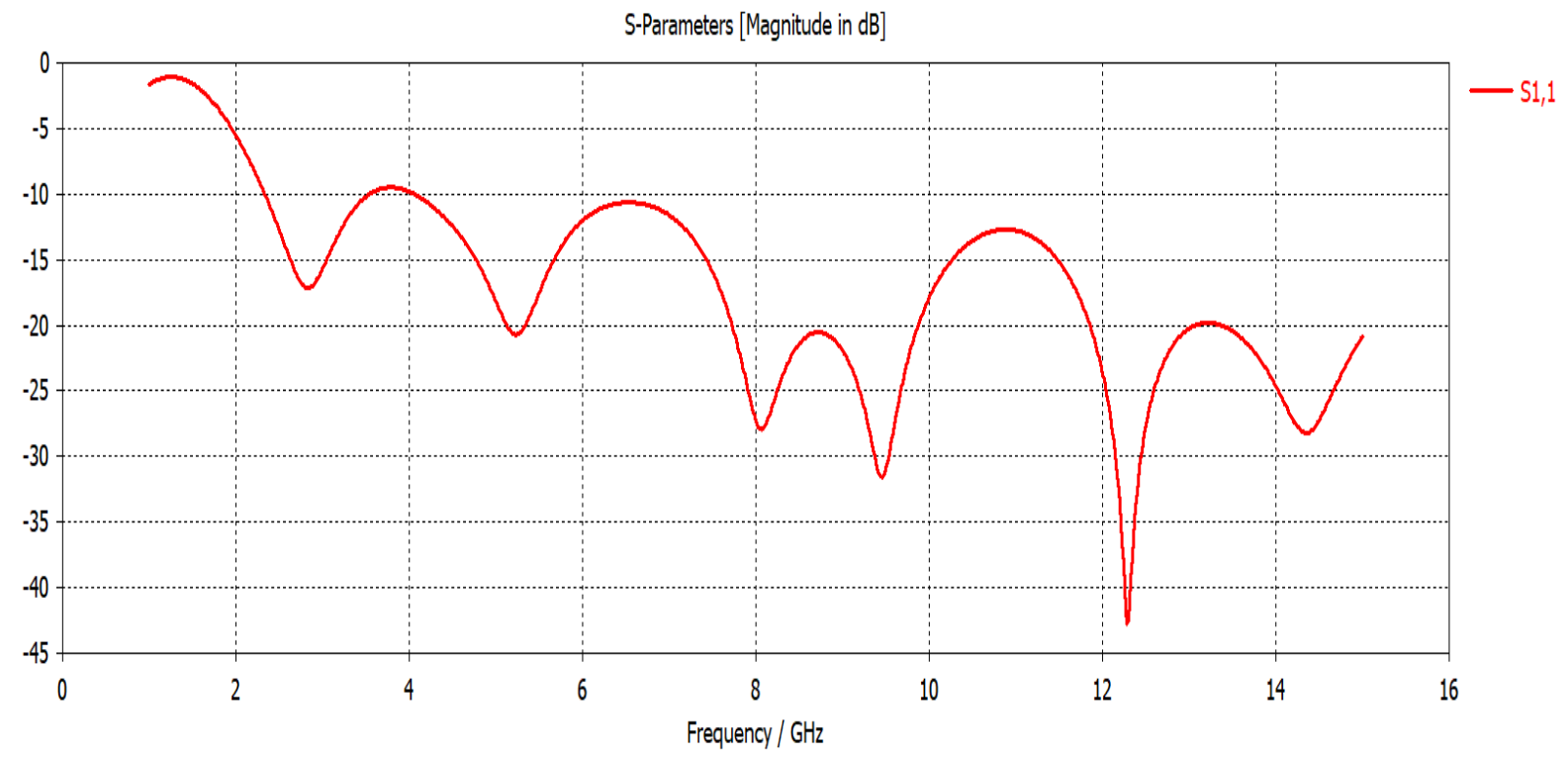

Figure 2 (a) S11 execution of proposed antenna

S-Parameters [Magnitude in dB]

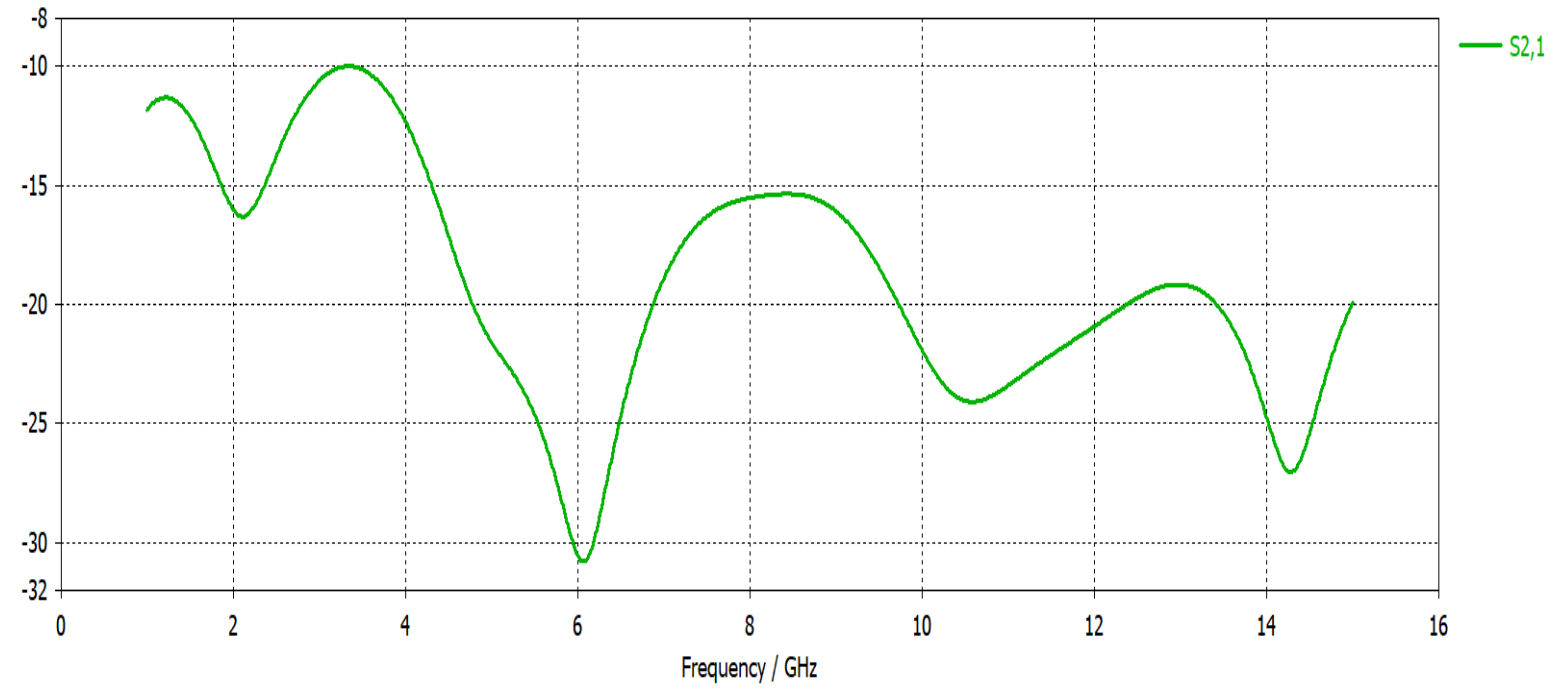

Figure 2 (b) S21 execution of proposed antenna

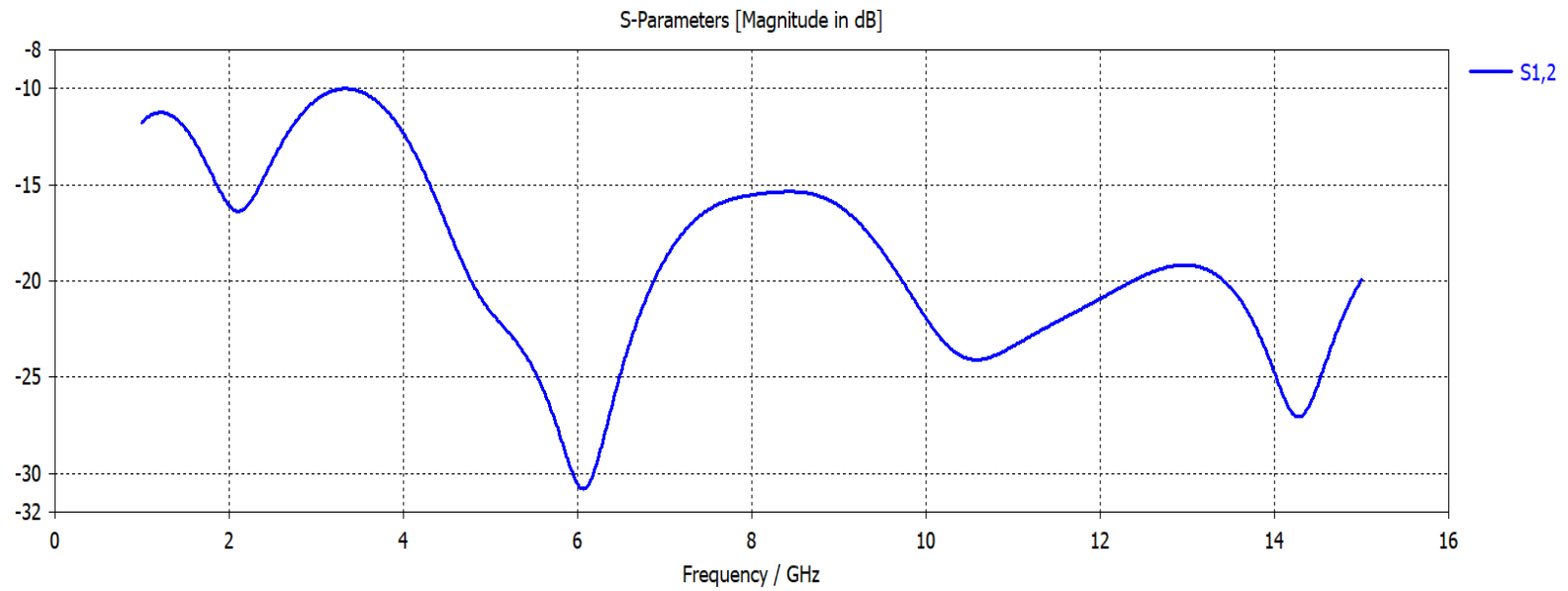

Figure 2 (c) S21 execution of MIMO-UWB antenna 


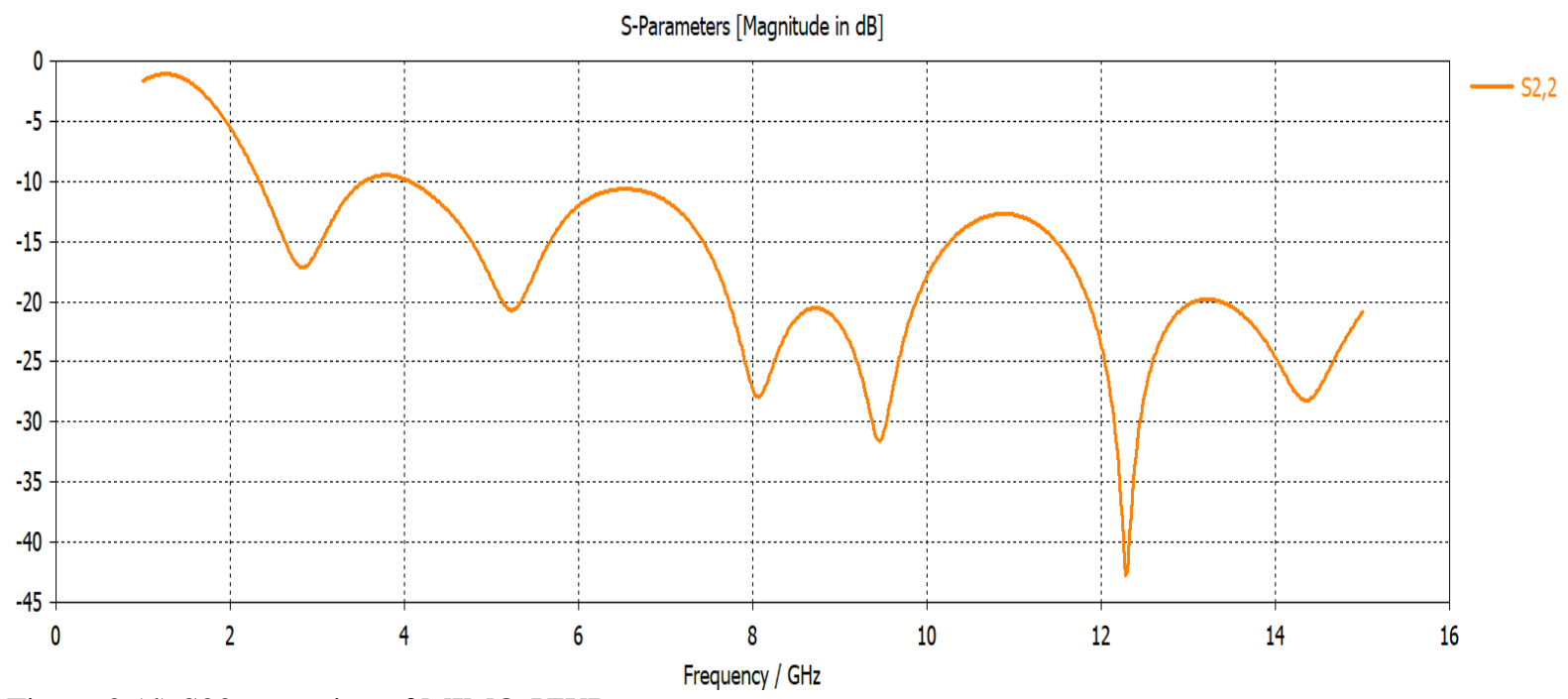

Figure 2 (d) S22 execution of MIMO-UWB antenna

The radiation pattern is used to express the characteristics of antenna radiation in the graphical method. The radiation pattern shows power, Electric field, Magnetic field, or distribution plot of gain around the antenna on azimuthal angle and elevation angle. It is normally expressed in $\mathrm{dB}$ or normalized dB. Radiation is the term used to address the emanation or gathering of wave front at the reception apparatus, determining its strength. In any delineation, the sketch attracted to address the radiation of a radio wire is its radiation design. One can essentially comprehend the capacity and directivity of a radio wire by viewing its radiation design. The radiation examples of the desiredantenna at 2.82, 5.23, 8.07, 9.45,12.28 are examined which is shown in figure 3(a), 3(b), $3(\mathrm{c})$ and $3(\mathrm{~d})$ with gain. At $\mathrm{F}=2.82 \mathrm{GHz}$ gain is $1.651 \mathrm{~dB}$, at $\mathrm{F}=5.23 \mathrm{GHz}$ gain is $4.041 \mathrm{~dB}$, at $\mathrm{F}=8.07 \mathrm{GHz}$ gain is $4.470 \mathrm{~dB}$ and at $\mathrm{F}=12.28$ gain is $6.438 \mathrm{~dB}$.

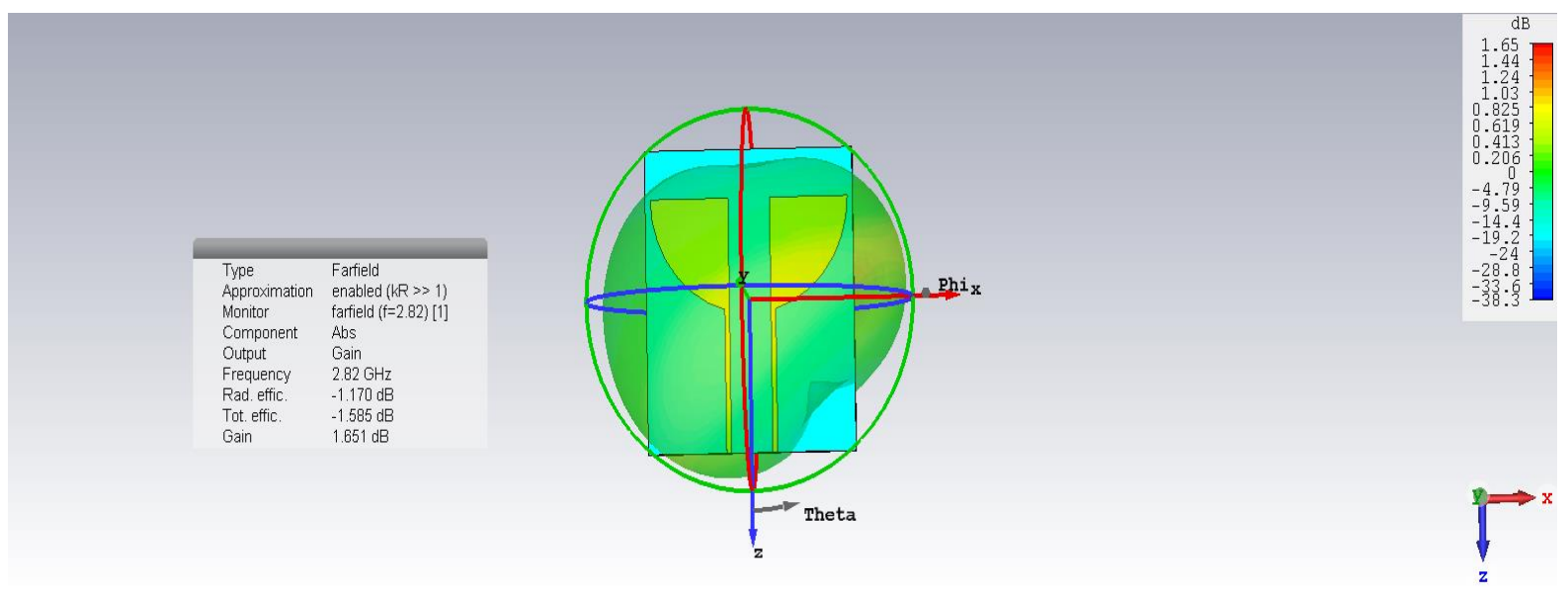

Figure.3(a) 3D Radiation patternat $\mathrm{f}=2.82 \mathrm{GHz}$

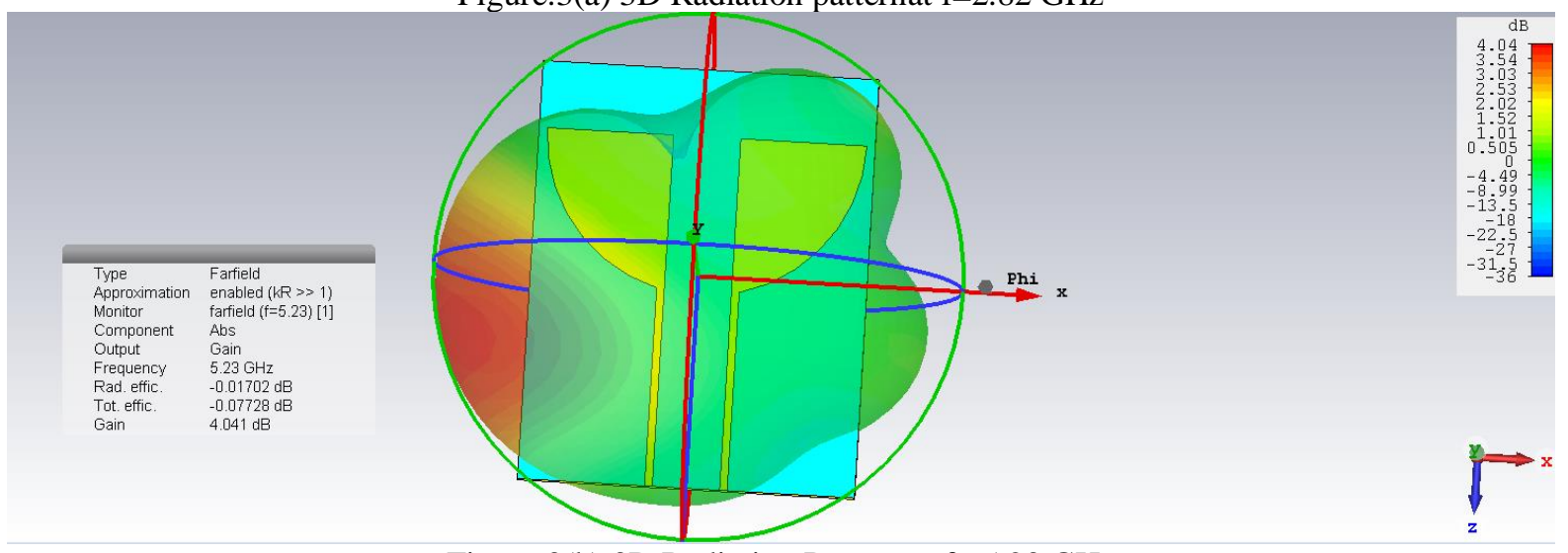

Figure 3(b) 3D Radiation Pattern at $\mathrm{f}=5.23 \mathrm{GHz}$ 


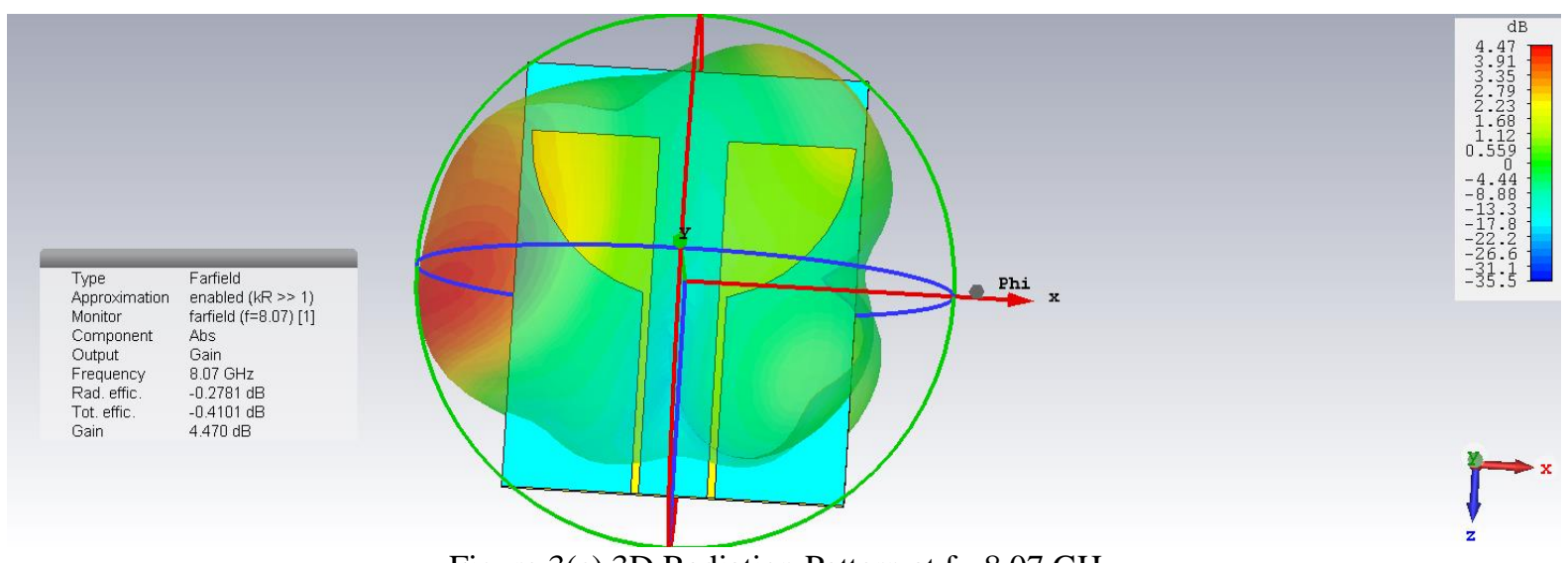

Figure 3(c) 3D Radiation Pattern at $\mathrm{f}=8.07 \mathrm{GHz}$

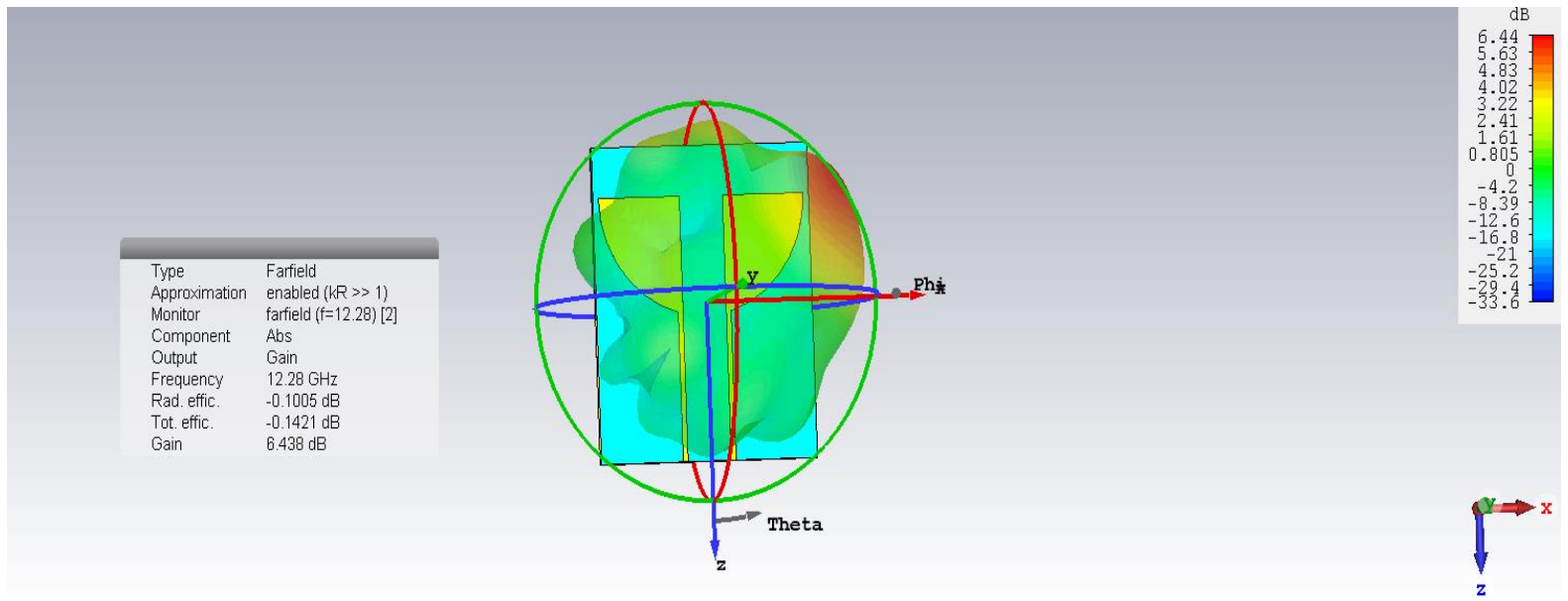

Figure 3(d) 3D Radiation pattern at $\mathrm{f}=12.28 \mathrm{GHz}$

By using CST software, Voltage standing wave ratio is obtained as under 2 where it is considered suitable for most antenna applications. The below figure 4(a) and 4(b) portrays the VSWR value below 2. Impedance mismatch of antenna and feeding system is calculated by voltage standing wave ratio. when there is high VSWR it indicates a high mismatch. Unity is the minimum value of VSWR this indicates a perfect match.

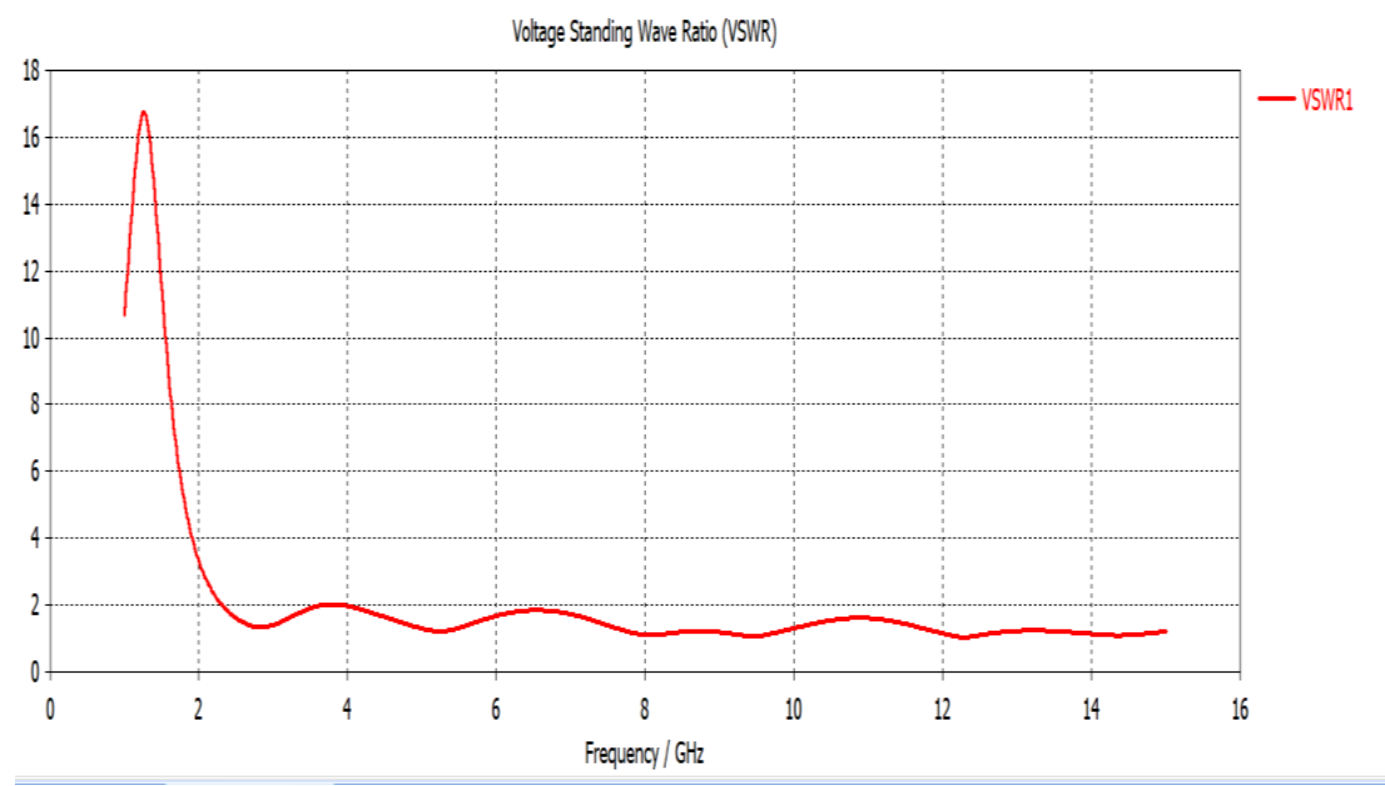

Figure 4(a) VSWR 1 


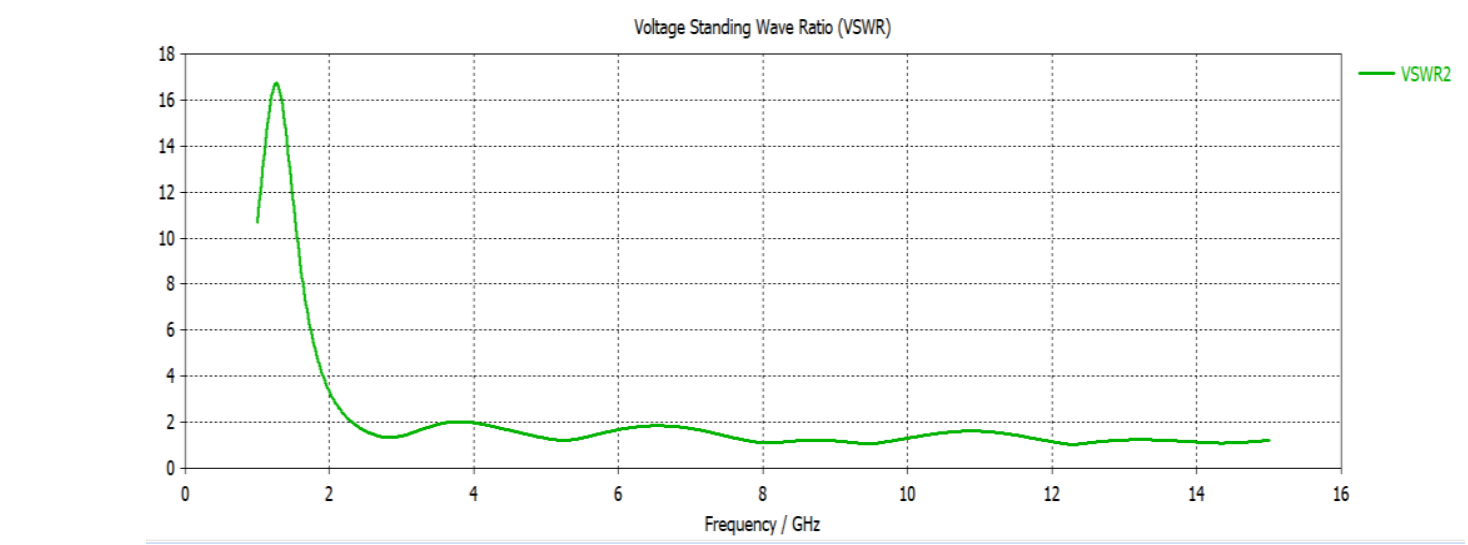

Figure 4(b) VSWR 2

\section{Conclusion}

Anenhanced Bandwidth of Dual Element MIMO Antenna is proposed to show the enhanced bandwidth for wireless applications, Ultra-wideband(UWB) for privileged applications. The dimensions of the antenna are 40 $\times 50 \mathrm{~mm} 2$. The proposed antenna achieves Ultrawide band which covers bandwidth from $2.3 \mathrm{GHz}$ to $14 \mathrm{GHz}$. The design with quarter circular radiating patches with a distance of $8 \mathrm{~mm}$ for wireless applications $>-15 \mathrm{~dB}$, which is better bandwidth. By using CSTsoftware,the proposed antenna with defected ground structure for wireless applications from $2.3 \mathrm{GHz}$ to $12.3 \mathrm{Ghz}$ is obtained.

\section{REFERENCES}

1. K. Pushpalatha1, "Design of Combined UWB and MIMO UWB Antenna for Mobile Terminals," 4th International Conference on Advances in Electrical, Electronics, Information, Communication and BioInformatics (AEEICB-18), pp. 100-120, 2018.

2. R. Munson, "conformal microstrip antennas and microstrip phased arrays," Antennas and propagation, IEEE transactions, vol. 22, no. 1, pp. 74-78, 1974.

3. y. m. kim, "ultrawide band technology and applications," nest group, vol. 10, pp. 20-30, 2003.

4. C. Y. Huang, "CPW-fed bow-tie slot antenna for ultrawideband communications," Electronics Letters, vol. 42, no. 19, pp. 1073-1074, Sept., vol. 42, no. 100, pp. 80-90, 2006.

5. J. Ren, "“Compact Printed MIMO Antenna for UWB Applications," IEEE Antennas and Wireless Propagation, vol. 13, pp. 1517-1520, 2014.

6. Z. Y. J. X. S. Zhang, "Ultrawideband MIMO/diversity antennas with a tree-like structure to enhance wideband isolation," IEEE Antennas and Wireless Propagation Letters, vol. 8, pp. 1279-1282, 2009.

7. W. L. Y. Li, "A printed diversity Cantor set fractal antenna for ultrawideband applications," ISAPE, vol. 14, pp. 34-38, 2012.

8. K. K. a. F. K. K. Hiraguri, "A wideband antenna a with Fshaped and Trapezoidal elements on printed circuit board for ultrawideband radio," IEEE 2nd Global Conference on Consumer Electronics, vol. 10, pp. 267-268, 2013.

9. H. Schantz, "Radiation efficiency of UWB antennas," IEEE UWST, 2002

10. S. Shoaib, " "Design and performance study of a dual-element multiband printed monopole array for MIMO terminals," IEEE Antennas and Wireless, vol. 13, no. 14, pp. 329-332, 2014.

11. C. H. S. G. S. Lin, "Isolation Improvement in UWB MIMO Antenna System Using Carbon Black Film," IEEE Antennas and Wireless Propagation Letters, vol. 16, pp. 222- 225, 2017.

12. J. howell, "microstrip antennas and propagation," IEEE transactions, vol. 23, no. 10, pp. 90-93, 1975.

13. S. Y. Lin, H. R. Huang, "Ultra-wideband MIMO antenna with enhanced isolation," Microwave and Optical Technology Letters, vol.51, no.2, pp.570-573, Feb. 2009.

14. Y. Li, W. Li, C. Liu and T. Jiang, "Two UWB-MIMO antennas with high isolation using sleeve coupled stepped impedance resonators," IEEE Asia-Pacific Conference on Antennas and Propagation (APCAP), pp.21-22, Aug. 2012

15. Balanis, Constantine, "Antenna theory - Analysis and Design ", John Wiley \& Sons Ltd, Reprinted 1997

16. M. A. Antoniades and G. V. Eleftheriades, "A compact multiband monopole antenna with a defected ground plane," IEEE Antennas Wireless Propagation. Lett., vol. 7, pp. 652-655, 2008.

17. K. H. Chiang and K. W. Tam, "Microstrip monopole antenna with enhanced bandwidth using defected ground structure,"IEEE Antennas Wireless Propagation. Lett., vol. 7, pp. 532-535, 2008. 
18. D. Nashat, H. A. Elsadek, E. Abdallah, H. Elhenawy, and M. F. 1skander, "Multiband and miniaturized inset feed microstrip patch antenna using multiple spiral-shaped defect ground structure (DOS)," in Proc. IEEE AP-S into Symp., Jun. 2009, pp. 1-4.

19. H. Schantz, "Planar Elliptical Element Ultra-Wideband Dipole Antennas", IEEE APS, 2002.

20. Chen, Z.N., and Chia, M.Y.W. "Impedance characteristics of trapezoidal planar monopole antenna", Microw. Opt. Technol. Lett., vol.36, no. 13, pp. 120-122, 2000. 